\title{
SEMINAR ON BIOMECHANICS
}

\author{
Leningrad, (U.S.S.R.) January 1973
}

The Seminar on Biomechanics devoted to the questions of hydromechanies in physiology of blood circulation was held in Lenigrad in January 1973. The meeting was organized by the Laboratory of Blood Circulation Physiology of the Pavlov Institute of Physiology of the Academy of Sciences of the U.S.S.R. and Institute of Mechanics of the Moscow State University. A number of scientists from Moscow, Lenigrad, Riga, Novosibirsk and Kharkov took part in the Seminar.

Three important problems of blood hydromechanics were subjected to a detailed discussion: aggregation phenomena in blood, filtration processes in tissues and mechanical characteristics of blood vessels.

V. A. Levtov (Lenigrad) reported on the main results of his experiments carried out in the Pavlov Institute of Physiology of the Academy of Sciences of the U.S.S.R. to elucidate the nature of light scattering by the flow of blood containing erythrocyte aggregates. He described possible ways of practical use of such experiments and theoretical problems arising in connection with their interpretation.

A. S. Popel (Moscow) gave a review of the optical experiments with blood and the possibilities of a theoretical calculation of light absorbtion and scattering by the blood flow. B. B. Zelikson (Leningrad) presented the results of model experiments where the dependence of electrical impedance on the condition of moving blood and the aggregation degree of erythrocytes had been studied. In the report made by N. H. Schadrina (Leningrad) theoretical approaches to investigation of the kinetics of erythrocytes aggregation were discussed. Some new interesting facts about rheological properties of blood and plasma were given in the reports by V. I. (jubskiy (Kharkov), D. V. Van'kov (Leningrad) and S. S. Grigoryan (Moscow).

The papers by B. I. Magbitch (Novosibirsk) and M. I. Titschenko (Leningrad) were devoled to the question of applying electrical methods for determination of quantitative characteristics of blood circulation (rheography). All these papers as well as that of Zelikson caused a most intensive and fruitful discussion.

S. A. Regirer (Moscow) contributed a paper concerning the transcapillary filtration in tissues and the application of multiphase models (in particular filtrational models) to describe the rheological properties of living tissues. The work was based on the results of investigations carried out at the Institute of Mechanics of the Moscow State University by the author and P. D. Usik. Ju. Ja. Kislyakov (Leningrad) presented a mathematical model of the filtration processes in the kidney.

S. A. Regirer and S. S. Grigoryan specially emphasized the advantages of the filtration models introducing such parameters as permeability and porosity for the description of blood circulation in tissues in comparison with the model of Poiseuille flow based on the concept of an "effective cylindrical vessel".

New experimental data on the propagation of pulse waves in the arteries were presented by N. A. Stepochkina (Leningrad). The paper of Ju. Ja. Kislyakov was devoted to the study of the model of the vessel wall as a multilayer membrane. The main point of both papers concerned the role of the active action of smooth muscles in blood vessels. V. V. Kilikovsky (Moscow) read a review paper which concerned the theoretical and experimental study of blood flow in large arteries and the characteristics of their walls.

I. V. Knets (Riga), S. A. Regirer, I. M. Skobeleva (Moscow) and V. I. Vorob'ev (Leningrad) reported on the work of the International Biophysics Congress, International Congress on Mechanics (Moscow, U.S.S.R.) and International Congress of Biorheology (Lyon, France) held in 1972. V. I. Vorob'ev spoke about the organizing and publishing activities of the International Society of Biorheology. All this information gave an idea about the modern state of investigations in the field discussed at the Seminar and about biorheological problems in general.

Institute of Cytology

V. I. BOROB'IN

Academy of Sciences of the U.S.S.R.

Leningrad 